\title{
Surface Modification of Polyaniline Film by Plasma-Graft Polymerization and Its Effect on the Redox Reaction
}

\author{
Kenji Yamada, Toshihide Haraguchi, and Tisato KajIYama* \\ Department of Chemical Engineering, Kitakyusyu National College of Technology, \\ Kitakyushu 803, Japan \\ *Department of Materials Physics and Chemistry, Graduate School of Engineering, \\ Kyushu University, Fukuoka 812, Japan
}

(Received July 28, 1997)

\begin{abstract}
Poly(vinylsulfonic acid) chains having cation-exchangeable groups are introduced onto a surface of polyaniline film by means of plasma-graft polymerization, and the redox reaction mechanism of the plasma-grafted polyaniline film is investigated with a combination of electrochemical and microgravimetric techniques. It becomes apparent from the surface analyses of the polyaniline film that poly(vinylsulfonic acid) chains are plasma-grafted. The graft area is not covered on all the surface of the film and is formed locally here and there on the surface. The plasma-grafted film exhibits both anion and cation migrations which take place in order to maintain electroneutrality of the film during the redox process in an electrolyte. The cation migration takes place predominantly through thickening of the graft layer composed of poly(vinylsulfonic acid) chains and extending of the graft area.

KEY WORDS Plasma-Graft Polymerization / Vinylsulfonic Acid / Polyaniline / Redox Reaction / Electroneutrality / Cation /
\end{abstract}

The use of cold, high frequency plasmas is exceedingly effective for modifying surfaces of solid materials. ${ }^{1-6}$ A plasma-graft polymerization method is an effective technique for surface modification of polymers by using plasmas. ${ }^{7,8}$ The surface of poly ( $p$-phenylene terephthalamide) fiber was modified to obtain a strong adhesion between the fiber and a matrix resin by plasma-graft polymerization method, in which the vinyl monomer having a functional group reactive with the matrix resin was plasma-grafted on the surface of the fiber and then covalent bonds were formed between the plasma-grafted fiber and the matrix resin. ${ }^{9-11}$

Polyaniline has the ability to be redox switched between oxidizing and reducing states. ${ }^{12,13}$ When the polymer is in the oxidized state in an electrolyte, anions are present to balance the positive charge created on the polymer backbone in order to maintain electroneutrality. ${ }^{14-16}$ The polymer backbone becomes neutral by reduction of the oxidized polymer and the anions go out of the polymer. If the thin layer containing cation-exchangeable groups is formed on a surface of polyaniline film, anions will be difficult to diffuse through the layer in the redox process and therefore cations instead of anions will at least partially contribute to the charge compensation process of the film. In this work poly(vinylsulfonic acid) chains having cation-exchangeable groups are bonded onto a surface of electropolymerized polyaniline film by means of plasma-graft polymerization, and the redox reaction mechanism of the plasmagrafted polyaniline film is investigated with a combination of electrochemical and microgravimetric techniques.

\section{EXPERIMENTAL}

\section{Plasma-Induced Polymerization}

Plasma-induced polymerization of vinylsulfonic acid should be investigated to ascertain the possibility of the plasma-graft polymerization onto a surface of polyani- line film. The aqueous solution containing $0.56 \mathrm{M}$ vinylsulfonic acid was placed in a round-bottomed flask and then was freeze-vaporized to remove dissolved oxygen gas. Plasma was generated at $13.56 \mathrm{MHz}$ at $100 \mathrm{~W}$ for $60 \mathrm{~s}$ under moisture of the solution in the flask. The solution was left for $100 \mathrm{~h}$ at $293 \mathrm{~K}$ and then was placed in methanol with stirring to recover polymer aggregations. The polymer aggregations were dried in vacuo at room temperature.

\section{Plasma-Graft Polymerization}

Polyaniline film was electropolymerized by galvanostatic electrolysis at current density $5 \mathrm{~mA} \mathrm{~cm}^{-2}$ in the electrolyte which was $2.37 \mathrm{M} \mathrm{HClO}_{4}$ aqueous solution containing $0.52 \mathrm{M}$ aniline. The electrode assembly consisted of stainless steel plate (area: $1 \times 2 \mathrm{~cm}^{2}$ ) or shear mode $6 \mathrm{MHz}$ AT-cut quartz crystal (area: $1.33 \mathrm{~cm}^{2}$ ) coated with gold about $300 \mathrm{~nm}$ in thickness as a working electrode, $\mathrm{Ag} / \mathrm{AgCl}$ electrode as a reference electrode, and a platinum plate as a counter electrode. The charges consumed during electropolymerization were $2 \mathrm{C} \mathrm{cm}^{-2}$ and $0.15 \mathrm{C} \mathrm{cm}^{-2}$ for the stainless steel plate and the quartz crystal, respectively. The electropolymerized film were washed with pure water and dried in vacuo at room temperature.

Figure 1 shows schematic representation of the apparatus for plasma-graft polymerization of the films. The films electropolymerized on the stainless steel plate and quartz crystal were plasma-graft polymerized as described hereinafter. Vinylsulfonic acid was used as a monomer for plasma-graft polymerization. The aqueous solution containing $0.56 \mathrm{M}$ vinylsulfonic acid in a roundbottomed flask was freeze-vaporized to remove dissolved oxygen gas before applying to plasma-graft polymerization. Cocks A and B were closed and the sample vessel was evacuated by opening cock C. Then cock B was opened to introduce argon gas after closing cock $\mathrm{C}$ till the pressure of the sample vessel was not beyond 1 


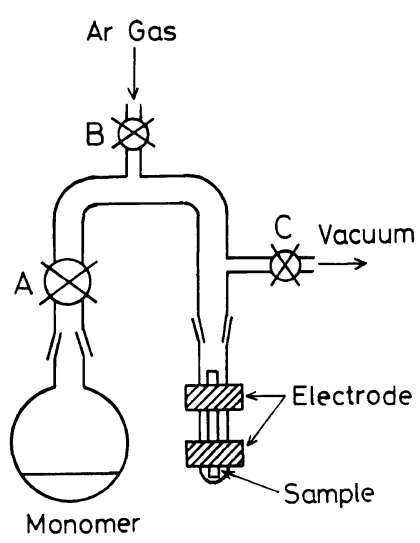

Figure 1. Schematic representation of the apparatus for plasma-graft polymerization.

atmospheric pressure. The air in the vessel was more exhaustively substituted to argon by repeating the above operations. Argon flow rate into the sample vessel was controlled with a gas flow controller under opening cocks $\mathrm{B}$ and $\mathrm{C}$. The film in the sample vessel was irradiated for $1 \mathrm{~min}$ with plasma which was generated at $13.56 \mathrm{MHz}$ at $100 \mathrm{~W}$ in the vessel being in an atmosphere of $0.15 \mathrm{Torr}$ argon and was encompassed all of the film surface. Then the monomer solution was poured into the sample vessel and the film was immersed to graft polymerize at $300 \mathrm{~K}$ in the monomer solution over periods of 10 to $120 \mathrm{~h}$. The film was washed with pure water after plasmagrafting and then was dried in vacuo at room temperature.

\section{Surface Analysis of Plasma-Grafted Film}

$\mathrm{X}$-Ray photoelectron spectroscopy measurement was carried out with a Shimadzu ESCA750 X-ray photoelectron spectroscopy (Shimadzu Co., Ltd.) to clarify the species of atoms constituting the graft layer. An infrared spectrum was measured with a 5DXB Fourier transform infrared spectroscopy (Nicolet Analytical Instruments) equipped with a Barnes analytical diffuse reflectance accessory to clarify chemical structure of the graft layer. The surface morphology of the film was observed by using a Nihondenshi JSM-6301FZ scanning electron microscope (Nihondenshi Co., Ltd.).

\section{Analysis of Redox Process}

A cyclic voltammogram and a mass change of the film which was formed on the quartz crystal as described previously were measured at the same time in propylene carbonate solution containing $0.01 \mathrm{M} \mathrm{LiClO}_{4}$ by using a Hokuto Denko HA-301 potentiostat/galvanostat (Hokuto Denko Co., Ltd.) equipped with a function generator and a piezoelectric quartz crystal microbalance. The film had been immersed in a large excess of the same $\mathrm{LiClO}_{4}$ solution before the above measurement. The potential sweep rate was $10 \mathrm{mV} \mathrm{s}^{-1}$ and the potential was cycled between -0.2 and $0.7 \mathrm{~V}$ ( $v s$. $\mathrm{Ag} / \mathrm{AgCl}$ ). Since the thickness of the film is small compared to the thickness of the crystal and the film is behaved in a rigid manner, the shear wave is not significantly damped. ${ }^{17}$ The resonant frequency obeys the Sauerbrey equation ${ }^{18,19}$

$$
\Delta f=-8.15 \times 10^{7} \Delta m / A
$$

where $\Delta m$ is a mass change and $A$ is piezoelectrically active area. The sensitivity for mass detection of the microbalance used was $16.3 \mathrm{ng} \mathrm{Hz}^{-1}$.

\section{RESULTS AND DISCUSSION}

\section{Plasma-Graft Polymerization}

In an infrared spectrum of the polymer aggregations which were obtained by plasma-induced polymerization of vinylsulfonic acid, an absorption peak attributable to $\mathrm{S}=\mathrm{O}$ stretching vibration of sulfonic group was recognized at $1050 \mathrm{~cm}^{-1}$, but the peaks attributable to $\mathrm{C}-\mathrm{H}$ out-of-plane bending and $\mathrm{C}=\mathrm{C}$ stretching vibrations which appear at $960 \mathrm{~cm}^{-1}$ and $1660 \mathrm{~cm}^{-1}$, respectively, in vinylsulfonic acid were not detectable. Therefore poly(vinylsulfonic acid) will be synthesized by plasmainduced polymerization of vinylsulfonic acid. It can be presumed that plasma-graft polymerization of vinylsulfonic acid is possible.

Figure 2 shows X-ray photoelectron spectra of a surface of polyaniline film electropolymerized on the stainless steel plate before and after plasma-grafting, and a diffuse reflectance infrared spectrum of a surface of the film after plasma-grafting. The peaks of $\mathrm{C}_{1 \mathrm{~s}}, \mathrm{~N}_{1 \mathrm{~s}}, \mathrm{Cl}_{2 \mathrm{p}}$, and $\mathrm{O}_{1 \mathrm{~s}}$ were recognized before plasma-grafting. The peaks of $\mathrm{C}_{1 \mathrm{~s}}$ and $\mathrm{N}_{1 \mathrm{~s}}$ are originated from polyaniline and the peaks of $\mathrm{Cl}_{2 \mathrm{p}}$ and $\mathrm{O}_{1 \mathrm{~s}}$ are done from $\mathrm{ClO}_{4}{ }^{-}$ions doped in the polyaniline film. After plasma-grafting the peak-heights of $\mathrm{N}_{1 \mathrm{~s}}$ and $\mathrm{Cl}_{2 \mathrm{p}}$ significantly decreased and both $S_{2 p}$ and $S_{2 s}$ peaks were newly recognized. Infrared absorption peaks attributable to $\mathrm{S}=\mathrm{O}$ stretching vibration of sulfonic group and $\mathrm{Cl}-\mathrm{O}$ stretching vibration of $\mathrm{ClO}_{4}{ }^{-}$ions appeared at $1050 \mathrm{~cm}^{-1}$ and $1160 \mathrm{~cm}^{-1}$, respectively. However the peaks attributable to $\mathrm{C}-\mathrm{H}$ out-of-plane bending and $\mathrm{C}=\mathrm{C}$ stretching vibrations which appear in vinylsulfonic acid were not detectable in the spectrum. According to a diffuse reflectance infrared spectrum of a surface of the film which was immersed for $90 \mathrm{~h}$ in the same monomer solution without being irradiated by argon plasma, the absorption peak attributable to $\mathrm{S}=\mathrm{O}$ stretching vibration was not detected, whereas the peak attributable to $\mathrm{Cl}-\mathrm{O}$ stretching vibration of $\mathrm{ClO}_{4}{ }^{-}$ions appeared. $\mathrm{ClO}_{4}{ }^{-}$ions could be exchanged with vinylsulfonic acid in the surface layer corresponding to the analytical depth of X-ray photoelectron spectroscopy which would be less than some nm. However the $\mathrm{ClO}_{4}{ }^{-}$ions will be difficult to be exchanged with vinylsulfonic acid ions during plasmagraft polymerization, since a certain amount of sulfonic acid groups bonded on the surface of the film will be formed in the initial stage of plasma-graft polymerization and the amount will increase accompanying the progress of the plasma-graft polymerization. The analytical depth of the infrared spectroscopy would be at least some tens of that of X-ray photoelectron spectroscopy and would offer structural information from both the graft layer and the polyaniline film. Therefore it was confirmed by the infrared spectrum that $\mathrm{ClO}_{4}{ }^{-}$ions doped during electropolymerization remain in the film after plasmagraft polymerization. It becomes apparent from the result of Figure 2 that poly(vinylsulfonic acid) chains are 

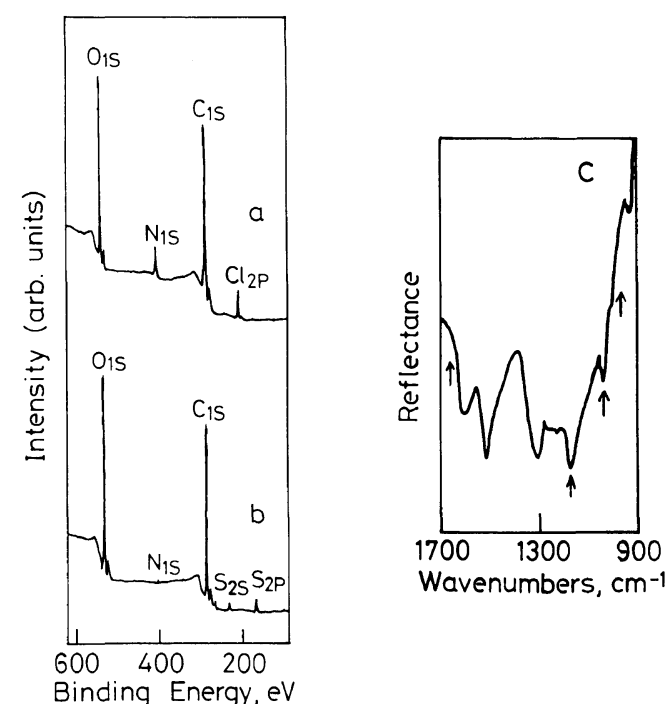

Figure 2. X-Ray photoelectron spectra of a surface of polyaniline film (a) before plasma-grafting and (b) after plasma-grafting for $40 \mathrm{~h}$, and (c) diffuse reflectance infrared spectrum of a surface of the film after plasma-grafting for $90 \mathrm{~h}$.
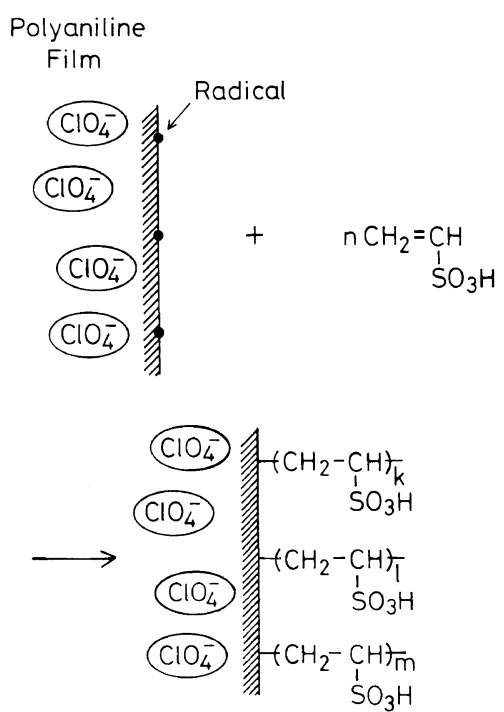

Figure 3. Plasma-graft polymerization process of vinylsulfonic acid onto a surface of polyaniline film.

plasma-grafted onto a surface of the polyaniline film and vinylsulfonic acid monomers are polymerized by active radicals which are formed on a surface of the film by plasma irradiation as shown in Figure 3.

\section{Redox Reaction Behavior}

Figure 4 shows scanning secondary electron micrographs of the film which was electropolymerized on the quartz crystal having vacuum-deposited gold before and after plasma-grafting. Microfibrillar aggregations are formed on the smooth surface of the film before plasmagrafting. According to X-ray photoelectron spectrum before plasma-grafting, $\mathrm{Au}_{4 \mathrm{f}}$ peak which is originated from gold coated on the quartz crystal was not detected, whereas the peaks of $\mathrm{C}_{1 \mathrm{~s}}, \mathrm{~N}_{1 \mathrm{~s}}, \mathrm{Cl}_{2 \mathrm{p}}$, and $\mathrm{O}_{1 \mathrm{~s}}$ were recognized. Therefore polyaniline film doped by $\mathrm{ClO}_{4}{ }^{-}$ ions will be covered over the whole surface of the quartz crystal. The microfibrillar aggregations composed of

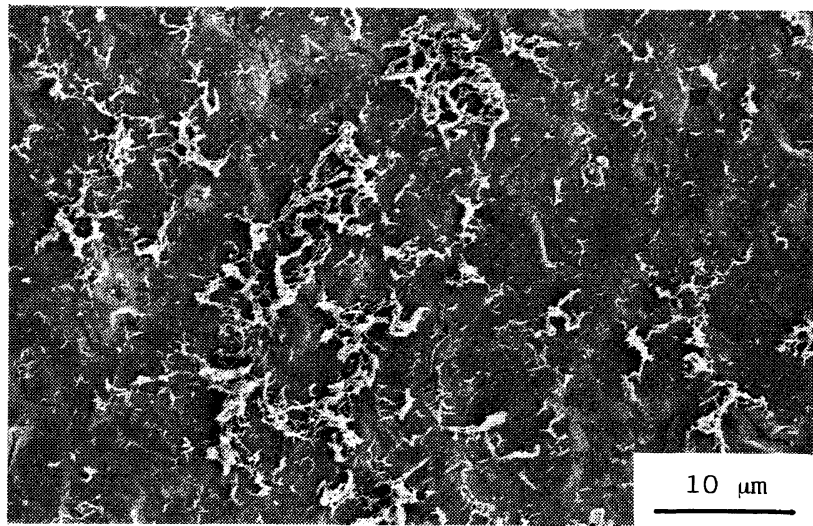

( a )

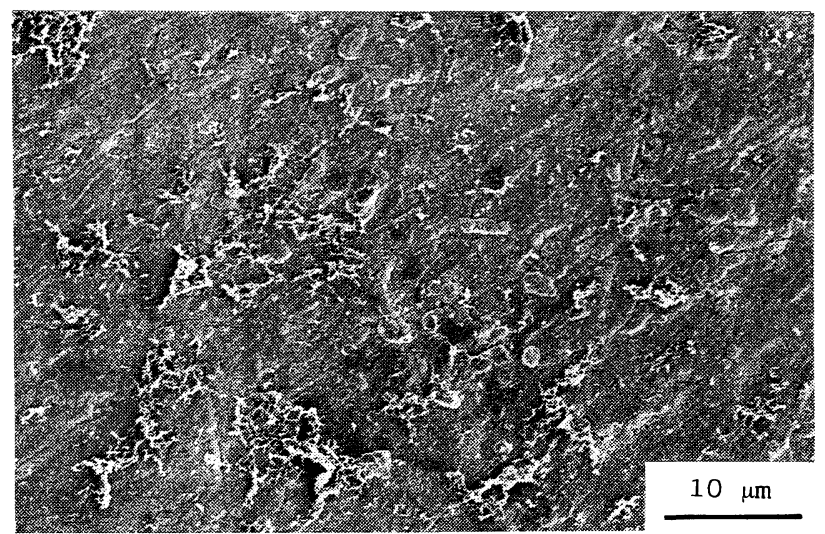

(b)

Figure 4. Scanning secondary electron micrographs of the polyaniline film (a) before plasma-grafting and (b) after plasma-grafting for $90 \mathrm{~h}$.

polyaniline chains were partly observed on the surface of the film and the film was in an initial state of development of the microfibrillar aggregations. A number of round granular aggregations were observed after plasma-grafting. It was confirmed by energy dispersive analysis that sulfur atoms contain in the aggregations and the aggregations are composed of poly(vinylsulfonic acid) chains. The granular aggregations would be grown by entangling graft chains and non-graft chains which are formed by chain transfer. Therefore the graft layer would be heterogeneously formed on a surface of the film.

The relative fraction of constituent atoms in the surface of the plasma-grafted polyaniline film can be evaluated from the X-ray photoelectron spectrum. Figure 5 shows the proportion of the peak areas of $S_{2 p}$ to $N_{1 s}$ as a function of polymerization time. The proportion of the peak areas of $S_{2 p}$ to $N_{1 s}$ was increased with increasing polymerization time. For example, the $S_{2 p} / N_{1 s}$ ratio evaluated from the film shown in Figure 4 was 1.4. If the thickness of the graft layer was always above that corresponding to the analytical depth of X-ray photoelectron spectroscopy, it would be evaluated from $\mathrm{S}_{2 \mathrm{p}} /$ $\mathrm{N}_{1 \mathrm{~s}}$ ratio that the fraction of graft areas is $58 \%$. However the fraction of areas of the granular aggregation shown in Figure 4 was much less than $58 \%$. It can therefore be presumed that there are also the graft areas which were not grown up to the granular aggregations and the increase in the proportion corresponds to thickening of 


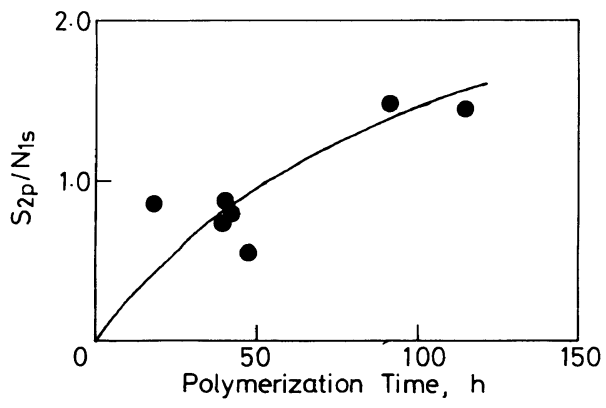

Figure 5. Proportion of the peak area $S_{2 p} / N_{1 s}$ as a function of polymerization time in plasma-grafted polyaniline film.
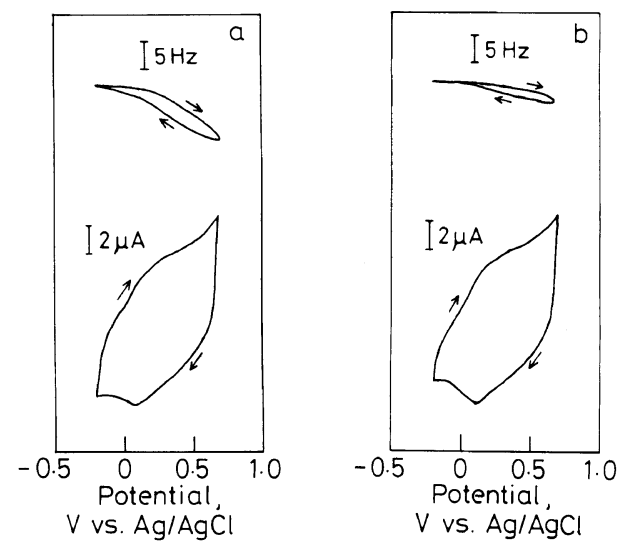

Figure 6. Cyclic voltammogram and mass change for redox process of polyaniline film under cycled potential at $10 \mathrm{mV} \mathrm{s}^{-1}$ : (a) before plasma-grafting and (b) after plasma-grafting for $90 \mathrm{~h}$.

the graft layer made up of poly(vinylsulfonic acid) chains and extending of the graft area. Thickening of the graft layer and extending of the graft area will be realized by increasing polymerization time.

Figure 6 shows a cyclic voltammogram and a mass change of the polyaniline film formed on the quartz crystal under cycled potential. The mass of the film increased during the oxidation process, whereas that decreased during the reduction process. The ability of redox reaction was almost unchanged before and after plasma-grafting, whereas the weight change of the film during redox reaction was depressed after plasmagrafting. In the polyaniline film $\Delta M_{\mathrm{q}} / \Delta M_{\mathrm{c}}$ was 0.67 before plasma-grafting, in which $\Delta M_{\mathrm{q}}$ and $\Delta M_{\mathrm{c}}$ represent the mass changes obtained from the quartz crystal and the charge, respectively. The value of $\Delta M_{c}$ was evaluated by assuming $\mathrm{ClO}_{4}{ }^{-}$ions migration. Deprotonation from polyaniline will not take place in $\mathrm{LiClO}_{4} /$ propylene carbonate solution. ${ }^{16,20}$ Therefore the result of $\Delta M_{\mathrm{q}} / \Delta M_{\mathrm{c}}$ will mean that both $\mathrm{ClO}_{4}{ }^{-}$and $\mathrm{Li}^{+}$ions migrate into the polyaniline film during the redox process. This explanation assumes that the mass change due to solvent motion is negligible compared to ion insertion or extraction ${ }^{19}$ and $\mathrm{Li}^{+}$ions are inserted to compensate for $\mathrm{ClO}_{4}{ }^{-}$ions which are doped deep inside the film. It will be difficult to take into consideration in the plasmagrafted film that charge balance is maintained via $\mathrm{H}^{+}$ ion insertion or extraction instead of the movement of $\mathrm{ClO}_{4}{ }^{-}$and $\mathrm{Li}^{+}$ions, since $\mathrm{SO}_{3}{ }^{-}$groups in the graft layer will be ion paired with $\mathrm{Li}^{+}$ions by immersing in a large excess of the $\mathrm{LiClO}_{4}$ solution before the redox process.

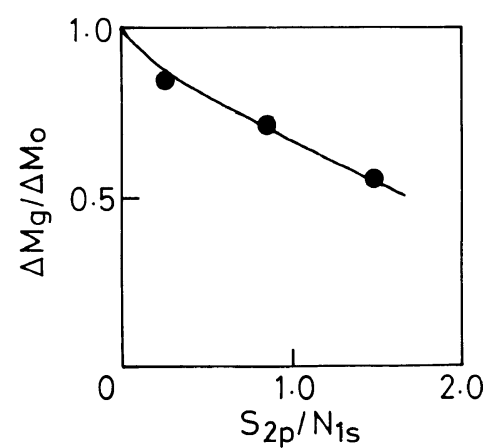

Figure 7. $\Delta M_{\mathrm{g}} / \Delta M_{\mathrm{o}}$ as a function of $\mathrm{S}_{2 \mathrm{p}} / \mathrm{N}_{1 \mathrm{~s}}$ in plasma-grafted polyaniline film.

Since $\Delta M_{\mathrm{q}} / \Delta M_{\mathrm{c}}$ became lower in the plasma-grafted film, $\mathrm{Li}^{+}$migration in the plasma-grafted film takes place more predominantly in order to maintain electroneutrality during the redox process, comparing with the ungrafted film. $\mathrm{Li}^{+}$ions are much more easily to migrate in the graft layer containing cation-exchangeable groups, comparing with $\mathrm{ClO}_{4}{ }^{-}$ions. Therefore in the reduction process $\mathrm{ClO}_{4}{ }^{-}$ions doped in the film are difficult to migrate into the electrolyte and therefore $\mathrm{Li}^{+}$ions in the electrolyte are introduced into the grafted film to maintain electroneutrality, whereas the $\mathrm{Li}^{+}$ions migrate into the electrolyte in the oxidation process.

Figure 7 shows $\Delta M_{\mathrm{g}} / \Delta M_{\mathrm{o}}$ ratio as a function of $\mathrm{S}_{2 \mathrm{p}} / \mathrm{N}_{1 \mathrm{~s}}$ ratio. $\Delta M_{\mathrm{g}}$ and $\Delta M_{\mathrm{o}}$ are the maximum weight change of the film per coulomb during the redox reaction in the grafted and the ungrafted films, respectively. $\Delta M_{\mathrm{g}} / \Delta M_{\mathrm{o}}$ ratio was decreased with increasing $S_{2 p} / N_{1 s}$ ratio. This result means that $\mathrm{Li}^{+}$migration during the redox process takes place more predominantly through thickening of the graft layer and extending of the graft area.

\section{CONCLUSION}

Vinylsulfonic acid having cation-exchangeable group can be plasma-graft polymerized onto a surface of polyaniline film. The development of the graft layer of which the thickness is ununiformed is realized by increasing polymerization time. Plasma-grafting is effective on the cation migration which takes place in order to maintain electroneutrality of the polyaniline film during the redox process in the electrolyte. The cation migration becomes predominant through thickening of the graft layer and extending of the graft area.

\section{REFERENCES}

1. J. R. Hollahan and A. T. Bell, Ed., "Techniques and Applications of Plasma Chemistry," Wiley-Interscience, New York, N.Y., 1974.

2. M. Shen, Ed., "Plasma Chemistry of Polymers," Marcel Dekker, New York, N.Y., 1976.

3. H. V. Boenig, "Plasma Science and Technology," Cornell University Press, Ithaca, New York and London, 1982.

4. H. V. Boenig, "Fundamentals of Plasma Chemistry and Technology," Technomic Publishing, Lancaster, PA, 1988.

5. G. Akovali, Ed., "The Interfacial Interactions in Polymeric Composites,' Proc. NATO-ASI, Series E: Applied Sciences, Vol. 230, Kluwer, Dordrecht, 1993.

6. M. Strobel, C. S. Lyons, and K. L. Mittal, Ed., "Plasma Surface Modification of Polymers: Relevance to Adhesion," VSP, Utrecht, 
The Netherlands, 1994.

7. M. R. Wertheimer and H. P. Schreiber, J. Appl. Polym. Sci., 26, 2087 (1981).

8. M. Suzuki, A. Kishida, H. Iwata, and Y. Ikada, Macromolecules, 19, 1804 (1986).

9. K. Yamada, S. Komono, T. Haraguchi, S. Ide, C. Hatanaka, and T. Kajiyama, Rept. Progr. Polym. Phys. Jpn., 37, 549 (1994).

10. K. Yamada, S. Komono, T. Haraguchi, and T. Kajiyama, presented at Taipei-Kyushu Joint Symposium on Chemical Engineering and Symposium on Transport Phenomena and Applications, National Taiwan University, Taipei, December 12-13, 1994, p 213-217.

11. K. Yamada, T. Haraguchi, and T. Kajiyama, J. Appl. Polym. Sci., 60, 1847 (1996).

12. J. C. Chiang and A. G. MacDiarmid, Synth. Met., 13, 193 (1986).
13. W. R. Salaneck, I. Lundstrom, W. S. Huang, and A. G. MacDiarmid, Synth. Met., 13, 291 (1986).

14. A. Kitani, J. Izumi, J. Yano, Y. Hiromoto, and K. Sasaki, Bull. Chem. Soc. Jpn., 57, 2254 (1984).

15. E. M. Genies, A. A. Syed, and C. Tsintavis, Mol. Cryst. Liq. Cryst., 121, 181 (1985).

16. T. Matsunaga, H. Daifuku, and T. Kawagoe, Nippon Kagaku Kaishi, 1 (1990).

17. M. R. Deakin and O. Melroy, J. Electroanal. Chem., 219, 321 (1988).

18. G. Sauerbrey, Z. Phys., 155, 206 (1959).

19. K. Naoi, M. Lien, and W. H. Smyrl, J. Electrochem. Soc., 138, 440 (1991)

20. M. Kaya, A. Kitani, and K. Sasaki, Chem. Lett., 147 (1988). 